\title{
Expert System for Flood Management in Lake Manapouri
}

\author{
Sandhya Samarasinghe, Dept of Natural Resources Engineering \\ Alan McKinnon, Centre for Computing \& Biometrics \\ John Bright, Agricultural Engineering Institute \\ Lincoln University, Canterbury \\ New Zealand
}

\begin{abstract}
Flood water in Lake Manapouri is released according to strictly formulated flood rules. The Realtime Flood Assistant is an expent system which incorporates Lake Manapouri flood rules and the experience of the control room operators at Transpower $N Z$ Ltd. to assist them in the release of flood water. The expert system is being developed in Level5 Object. The program is mainly an event-driven system based on forward chaining inferencing in conjunction with object oriented methods. Backward chaining inferencing is used only at the beginning of the program to establish initial data. With the use of built-in clocks, the expert system runs in real-time, assisting the operators with the release decisions which are made about every $11 / 2$ hours.
\end{abstract}

\section{Lake Manapouri and floods}

Lake manapouri is in the Waiau catchment located in the south western region of New Zealand (1). Water in Lake Manapouri is used mainly for continuous power generation at the power station located on the west arm of the lake and equipped with six generators capable of generating 14 GegaWatt-Hours (GWH) a day. Flood history for the last five years indicates that there can be about 2 to 5 floods a year in Lake Manapouri and they can last from several weeks to several months. In a flood situation, the power generation is maximised to pass as much water as possible through the turbines to the sea. If flood conditions persist, the extra water is released through four spill control gates into the Waiau river according to strict flood rules formulated by the guardians of the lake $(2,3)$. The Electricity Corporation of New Zealand (ECNZ) is responsible for the Lake Manapouri flood management, and the failure to adhere to the flood rules precisely can lead to warnings or penalties imposed by the guardians of the lake.

\section{Flood rules for Lake Manapouri}

A flood situation arises when the lake level rises above the Maximum Control Level (MCL) of the lake. If full power generation capacity is available, the MCL is $178.6 \mathrm{msl}$ (metres above sea level) at which the designed flood region begins. However, if all the generators are not available due to annual maintenance or failure, or full generation capacity cannot be met due to the low power demand, MCL is reduced to provide extra flood storage.This is done according to a table which shows MCL as a function of daily power generation and number of generators.

For a given MCL, the four spill control gates are opened to release flood water according to a release table which provides the required release (in metres per second) corresponding to various heights of the lake above MCL. However, releasing flood water isnot straight forward. Before making a release decision, the operators must consider the past release, current lake level and lake inflows, flood behavior, and flood rules in addition to consulting the tables already discussed. The spill control gate setting ischanged only if at least $11 / 2$ hours has elapsed since the previous change to avoid dangerously large amounts of water from flowing down the Waiau river. However, during this $11 / 2$ hour period, floods can develop quickly and the release table can dictate a much larger release than that can be permitted for the next $1 \frac{1 / 2}{2}$ hour decision period 
because flood rules allow only gradual release changes consisting only one step up or down the release table to prevent rapid changes in the Waiau river flow. This rule complicates the flood operation in a rapid flood situation, and therefore, rapidly rising floods should be carefully controlled, always keeping in mind the dangers and penalties associated with incorrect decisions.

When a flood recesses, the release should be decreased. However, as for a developing flood, a recessing flood can cause fluctuations in the lake level and operators must control the flood carefully to avoid rapid river flow changes. Moreover, a recessing flood can again grow into a rapidly developing flood, and there can be several flood peaks during a single flood period.

Additionally, the total power generated by the Manapouri plant can change almost daily to alleviate the flood conditions or to accommodate changing electricity demand. This must be incorporated into the release decision because the MCL varies with the power generation. Consequently, after each power rescheduling event, the reference lake level for the flood (MCL) changes and therefore, the flood situation changes. Currently, all these changes and release decisions are recorded by hand each time changes occur and new release decisions are made based on this recorded information. This process has become confusing to the staff and can lead to wastage of useful water and/or inefficient flood management practices. Moreover, managing a flood while attending to the major task of continuous power generation has become even more complex a task for the staff.

Following is a brief description of an expert system being developed to assist operators successfully release flood water throughout the flood period.

\section{Expert System Model Development}

In the past, few attempts have been made to forecast floods using mathematical models involving nonlinear programming, unsteady flow routing etc. (4,5); however, the potential use of expert systems for water resource management has already been ecognized (6).

The flood assistant expert system is being developed in Level5 Object (6) that runs under windows 3.0. The flood operation described above is dynamic in nature in that operators respond to changing system parameters in the release of flood water. This requires an event-driven expert system approach to mimic the decision process. Therefore, a forward chaining mechanism in conjunction with object-oriented methods (called WHEN CHANGED methods in Level5Object) is used as the basis of the expert system. In forward chaining inferencing, the available information is used by the inference engine to deduce new knowledge from forward chaining rules (called demons in Level5Object). Whenever, new knowledge is added to the knowledge base, the forward chaining inference engine immediately attempt to use it to fire more demons to deduce more facts. Methods are activated as a result of firing demons or from other methods. A goal-driven backward chaining inferencing is used only in the initial part of the program to query the operator to obtain initial flood data.

Domain knowledge for the expert system is the flood rules and the flood control operators' experience in managing floods in Lake Manapouri. Some rules were obtained through conversations with the operators and from published information. However, the difficulty associated with the knowledge acquisition is that the operators are busy with power generation and that they cannot remember all the details of flood management. In Level5 Object, the problem domain is represented by objects. For example, lake, power plant, etc. are objects. The objects have properties called attributes: The attributes of the lake are lake level, inflow, maximum control level (MCL), release, etc. and those of the power plant are number of machines, planned 24 hour generation, etc. Objects have instances with the same attributes as those of the object. For example, Manapouri is an instance of lake and Manapouri Plant is an instance of power plant. Using instances and their attributes, flood rules were represented by a combination of backward chaining rules, forward chaining demons, and methods (6). Methods are used for extracting appropriate flood data, procedural comparisons, triggering demons, and for activating timers.

The Level5 Object environment provides an extensive facility for designing the user interface. In this program, displays, hyperregions, pushbuttons, pictureboxes, bitmap images, promptboxes, etc. are used for effective communication with the user.

\section{Expert system operation}

At the beginning, the program runs in backward chaining mode to establish MCL. Then the decision making begins in forward chaining mode according to the flow chart shown in Figure 1 . For each $11 / 2$ hour decision making period, the flood condition is evaluated and the operator is informed of the nature of 
the flood, i.e., if the flood water is rising or recessing rapidly or slowly, etc. Then the required volume of release for that period is indicated and timers are activated for $11 / 2$ hours. Timer objects in conjunction with demons and methods are used to hold the elapsed time and to flash various animated icons during this period to visually indicate to the operator to wait till the next release decision. Frequent changes in power generation can be easily input by clicking on a hyperregion which activates a demon that incorporates it into the next release decision. At the control room, operators change every eight hours, and new operators can quickly update themselves on the flood situation by clicking on a pushbutton which triggers a demon and a method to display data. Some details of the operation of the expert is given below.
RULE for reduced MCL

IF level OF Manapouri > 177.8

AND no. of machines OF Man plant $<6$

OR 24 HR generation OF Man plant $<13$

THEN flood at reduced MCL.

Figure 2. A backward chaining rule

Depending on the success or failure of the rule several paths can be taken to establish MCL. Once the initial flood conditions have been established, the expert system switches into a forward chaining mode for the rest of the flood period for making decisions in conjunction with methods. For example, if the rule in Figure 2 is fired, forward chaining inference engine immediately considers the following demon for firing .

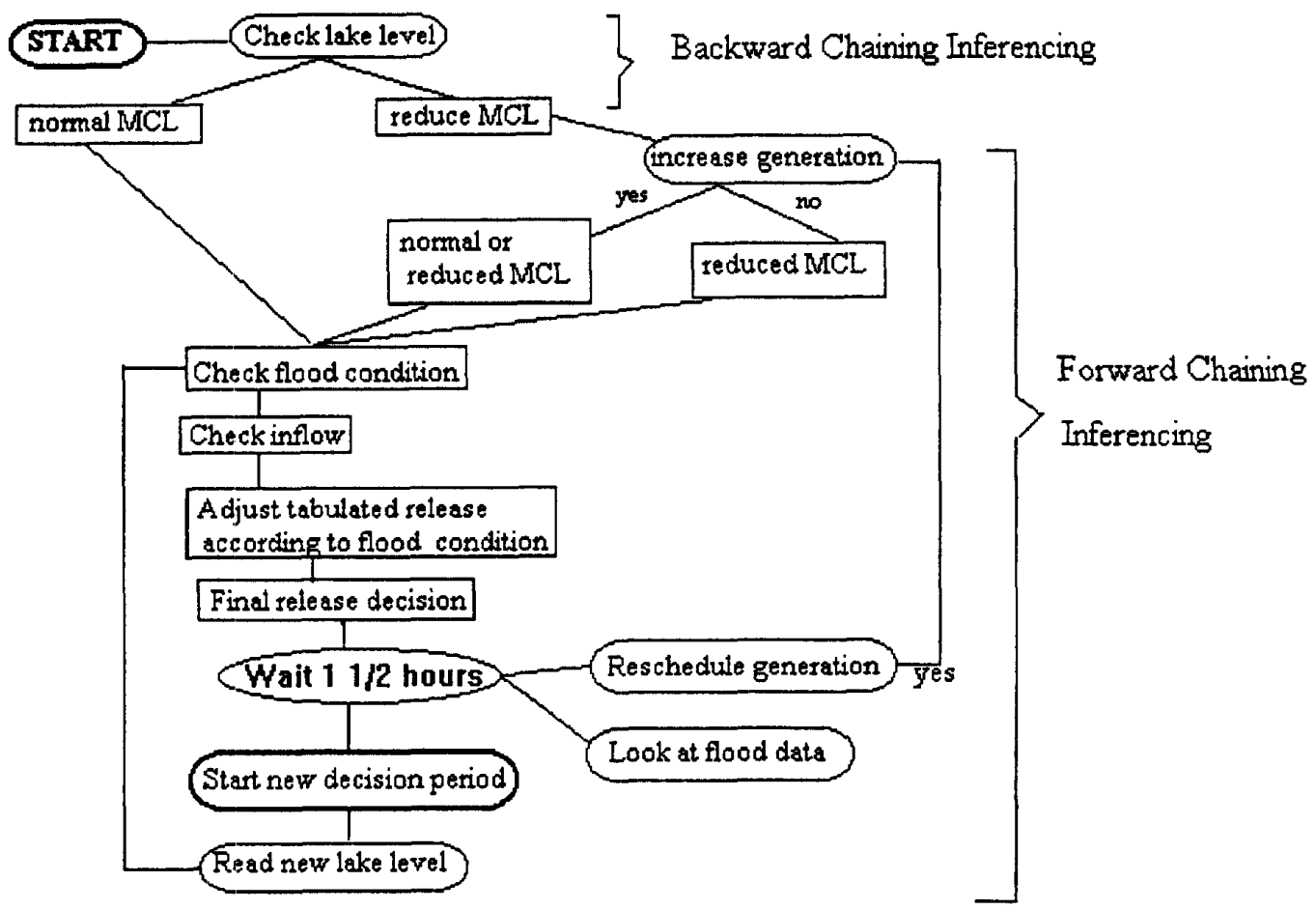

Figure 1. Flow chart for the expert system

The program begins by querying the operator about lake level, amount of power generation, etc., to determine the MCL. An example of a backward chaining rule is shown in Figure 2.
DEMON for incorporating rescheduled generation ASK increase generation possible? displayIF flood at reduced $\mathrm{MCL}$

AND increase generation possible = TRUE

THEN ASK planned 24 HR generation AND read MCL : = TRUE

Figure 3. A forward chaining demon 
In the processing of the demon in Figure 3, it is queried if power generation can be increased to avoid the reduction in MCL because the objective is to reduce the amount of spill. Depending on the answerto this query, two paths can be taken by the inference engine. The path taken if the demon fires is that a message is sent to the Method called "read MCL" to read appropriate MCL. This method (not shown) contains information shown in Table 1 . It also sends a message to a method called "read cumec release" (Figure 4) to activate it itself.

\section{METHOD read cumec release BEGIN \\ check flood condition : = TRUE}

level above MCL OF Manapouri := level OF Manapouri - MCL OF Manapouri

IF (level above MCL OF Manapouri > 0) AND

(level above MCL OF Manapouri $<=0.03)$ THEN

cumec release of Manapouri : $=30$

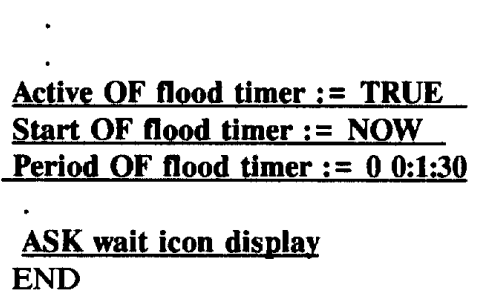

Figure 4. An object-oriented method

When the method in Figure 4 is activated, a demon is triggered to evaluate the behavior of the flood, a release decision is made, a flood timer is activated for $11 / 2$ hours, and an animated display is activated to tell the operator to wait for $11 / 2$ hours. The latter display also contains a pushbutton and a hyperregion to enable the operator to look at past data and also incorporate a new schedule for power generation. When the pushbutton or the hyperregion is clicked on, either a demon and/or a method with proper instructions are activated to carry out the necessary task. The time remaining until the next release is also displayed in a value box in the above display. Once the timer has tripped, another demon is triggered activating a display which guides the operator through the next decision making period. This process is repeated every $11 / 2$ hours throughout the flood period until the spill control gates have been gradually closed.

\section{Summary and Conclusion}

A real-time expert system is currently being developed to assist with the management floods in Lake Manapouri. Using backward chaining and forward chaining mechanisms, object oriented methods, and built-in clocks, it makes decisions on the amount of water to be released every $11 / 2$ hours throughout the flood period. It regularly reports on the behaviour of the flood, incorporates frequently changing power generation into release decisions, and updates the shift operators on the flood history to allow them to continue managing the flood successfully. The expert system can also be a useful tool for training novice operators to manage floods in Lake Manapouri by creating hypothetical floods or controlling floods which have occurred in the past. The prototype will be validated by comparing its decisions with those of the operators. It will also be linked to a database programme to store flood data for later use.

\section{Acknowledgements}

We thank Mr. Tony Silke, Mr. Doug Spencer, and control room operators at Transpower NZ Ltd. in Christchurch for providing information and to ECNZ for allowing us to use the information contained in this paper.

\section{References}

(1) Manapouri Hydro Power Station, March 1990, Brochure produced by Electricity

Corporation of New Zealand (ECNZ).

(2) Lakes Manapouri and Te Anau Management, Condensed version of the lake operating procedures, Transpower NZ. Ltd.

(3) Manapouri Lake Control Flood Rules, December 1984 revision, ECNZ.

(4) Unver, O.I., L.W. Mays, and K. Lansey, RealTime Flood Management Model for Highland Lake Systems, September 1987, Journal of Water Resource Planning and Management. Vol. 113(5):620-637.

(5) Unver, O.I. and L.W. Mays, Model for Real-Time Optimal Flood Control Operation of a Reservoir System, 1990, Water Resource Management Vol.4:21-46.

(6) LEVEL5 OBJECT - Object Oriented Expert System for Microsoft Windows. User's and reference Guides. Information Builders, Inc. 1250 Broadway, NY10001 